\title{
Hydraulic Performance of Sharp-Crested Labyrinth Weir
}

\author{
${ }^{1}$ Rangeen Sh. Mohammed, ${ }^{2}$ Shaker A. Jalil \\ ${ }^{1}$ College of Engineering, Nawroz University, Kurdistan Region-Iraq \\ ${ }^{2}$ Water Resources Department, University of Duhok, Duhok, KRG
}

\begin{abstract}
Weirs are used as a control structure in the waterways. Among the influencing geometrical parameters on the performance of weir is the total crest length. The length increases the efficiency of the two-cycle Labyrinth sharp-crested up to 2.5 times the discharge of normal weir. Experimental work on 27 geometric models of a two-cycle Labyrinth sharp-crested weir indicates that the shortest models' performances better. The weirs of the wider apex and the same total length perform better and its coefficient of discharge $(\mathrm{Cd})$ is higher, the highest mean value is 0.62 for the wide apex width. Labyrinth weirs of longer sidewall length and contents same apex width performance batter. The larger value of sidewall angle and for a constant apex width increases the value of discharge coefficient. The long sidewall length causes a flatter water surface profile generates on the crest. The equations to predict the value of the discharge coefficient are suggested within the limitations of the present study.
\end{abstract}

Keywords: Labyrinth weir, coefficient of discharge, dimensional analysis, SPSS, Neural Network.

1.

Weirs are used for controlling the water in many projects such as irrigation projects and diverting the flow from the main channel to the weirs. The labyrinth weirs are a type of weir that has a long length compares to the normal weir, which gets a higher discharge capacity. Many researchers study the performance and behavior of labyrinth weirs and their geometry. Taylor (1968) tested (24) models of the labyrinth weirs with different configurations. Most of these models are triangular weirs and some of the rectangular and trapezoidal weirs and compared his results with sharp-crested weirs and recommended that $\mathrm{w} / \mathrm{P}$ should $>2$. Tacail et al. (1990) found a model for trapezoidal labyrinth weir. They found the two-cycle labyrinth weirs are more efficient than the three-cycle labyrinth weirs for the same channel width. Sitompul (1993) used many types of labyrinth weirs and found the performance of trapezoidal labyrinth weirs is better than rectangular labyrinth weirs. Wormleaton and Tsang (2000) tested the aeration of the sharp-crested normal weir and

\section{Introduction}

labyrinth weir; they found the aeration performance of the labyrinth weir is better than normal weir. Savage et al. (2004) and Paxson and Savage (2006) predicted the hydraulic performance of labyrinth weir by numerical modeling, which is a tool for design also found the more flow can pass at the lower head. Willmore (2004) tested labyrinth weirs with two cycles and $\left(7^{\circ}\right.$ to $\left.35^{\circ}\right)$ and found the labyrinth weir with half-round crest pass more flow than the quarter-round crest. Tullis et al. (2007) tested three labyrinth weir with sidewall angles $\left(7^{\circ}, 8^{\circ}\right.$, and $\left.20^{\circ}\right)$ and found an empirical equation for calculating the head in the submerged condition of flow. Ghare et al. (2008) put the best hydraulic design for an economical trapezoidal labyrinth weir. Crookston (2010) tested 30 models of trapezoidal labyrinth weir with sidewall angles $\left(6^{\circ}\right.$ to $\left.35^{\circ}\right)$ to find the discharge coefficient $(\mathrm{Cd})$ and found the half-round crest is more efficient for $\mathrm{H} / \mathrm{P} \leq$ 0.4. Khode and Tembhurkar (2010) recommended value of vertical aspect ratio $(\mathrm{w} / \mathrm{P})$ should be not $<2$ for trapezoidal weirs and not $<2.5$ 
for triangular labyrinth weirs. Crookston and Tullis (2011) tested the orientation of labyrinth weir where the apex connected to the flume wall at the upstream called "normal orientation" but when connected in the downstream called "inverse orientation". Khode et al. (2011) found the value of the discharge coefficient (Cd) for labyrinth weir increased with increasing the sidewall angles. Carollo et al. (2011) tested four sharp-crested triangular labyrinth weirs in shape (W-planform) with sidewall angles $\left(30^{\circ}, 45^{\circ}\right.$, $135^{\circ}$, and $150^{\circ}$ ) and found the cycle number $(\mathrm{N})$ is not the important factors that influence in the flow capacity. Crookston and Tullis (2012) studied the influence of $(\mathrm{w} / \mathrm{P})$ on the efficiency of labyrinth weir discharge and found this ratio is important in the accuracy of the design. Crookston and Dabling (2012) used 4 models with four cycles and a sidewall angle $\left(15^{\circ}\right)$. They suggested the equation for finding $(\mathrm{Cd})$ depending on the ratio of $\left(\mathrm{H}_{\mathrm{t}} / \mathrm{P}\right)$. Khode et al. (2012) found the discharge coefficient $(\mathrm{Cd})$ for trapezoidal labyrinth weir with two-cycles and sidewall angle $\left(8^{\circ}\right.$ to $30^{\circ}$ ) decreased with decreased sidewall angle. Mirnaseri and Emadi (2013) found the discharge of rectangular combined weir with a gate is more than the discharge of sharp-crested weir with a gate for $\left(\left(\mathrm{H}_{t} / \mathrm{P}\right)\right.$ less than 0.6. Suprapto (2013) recommended the trapezoidal labyrinth weir for the best design of spillway due to the high capacity. Anees K. Idrees et al. (2016) studied the effect of the sidewall angle (a) on the discharge coefficient (Cd) for the flow over one-cycle compound trapezoidal labyrinth weirs and they found the weir orientation doesn't affect the efficiency of the discharge. Omer Bilhan and M. Emin Emiroglu (2016) and Abbasi et al. (2020) found the value of discharge for labyrinth weirs with different weir height and sidewall angles $\left(12^{\circ}\right.$ to $\left.37^{\circ}\right)$ is higher than the normal weirs.

\section{THEORETICAL BACKGROUND}

The labyrinth weir is used for increasing the effective length of the waterway for a limited width of the channel. Fig. (1) shows a top view and section of the Labyrinth weir. The equation of discharge over the sharp-crested weir is derived by considering ideal nappe flow over the weir crest (Chow, 1959), according to this, the integration of the total head of an element strip of a thickness (dh) leads to the theoretical weir discharge equation (Qth) (Subramanya, 2009). The actual discharge (Qact.) passing the crest of the labyrinth weir is based on the theory of normal weir, which is given by (Horton, 1907) in equation (1). This equation is also given by (Hicks and Slaton, 2014) for actual discharge (Qact) in equation (2).

$$
\begin{array}{r}
\mathrm{Q}_{\mathrm{th}}=\frac{2}{3} \sqrt{2 \mathrm{~g}} \mathrm{~L} \mathrm{~h}^{\frac{3}{2}} \ldots \\
\mathrm{Q}_{\mathrm{act}}=\frac{2}{3} \mathrm{Cd} \sqrt{2 \mathrm{~g}} \mathrm{~L} \mathrm{~h}^{\frac{3}{2}}
\end{array}
$$

Where $\mathrm{Cd}$ is discharge coefficient $\left(\frac{\mathrm{Q}_{\mathrm{act}}}{\mathrm{Q}_{\mathrm{th}}}\right), \mathrm{g}$ is the gravity acceleration, $\mathrm{h}=$ Head of water above weir crest, and $\mathrm{L}=$ Crest length where the crest length is longer than the channel width (B). The theoretical value of discharge increases with the increase of the effective length (L). So by dividing the actual discharge by the theoretical discharge will decrease the value of $\mathrm{Cd}$.

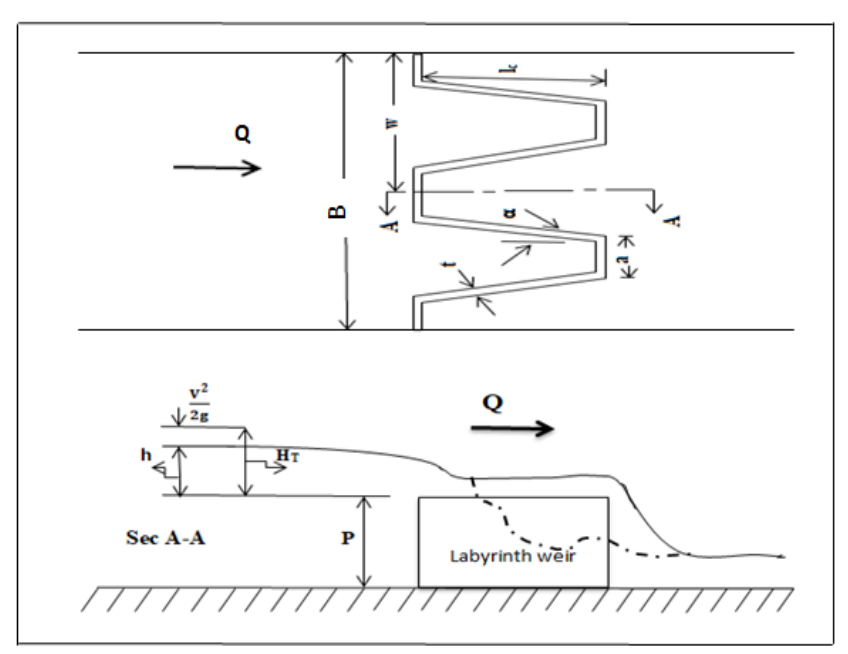

Fig. (1): Definition sketch of a top view and section of Labyrinth weir.

Referring to Fig. (1) and depending on the study of (Sangsefidi et al., 2018) the discharge passing over 
the labyrinth weir depends on the parameters of geometry (L, P, B, a, and a), where (P: Height of weir, B: Channel width, a: apex width a: Sidewall angle) and parameters of hydraulic $(\rho, h, H, v$, and $\sigma)$ where (H: Total upstream water head, $\rho$ : The mass density of water, v: Kinematic viscosity of water, and $\sigma$ : The surface tension of the water). By using dimensional analysis, the Buckingham Pi-theorem, and depending on earlier studies (Sangsefidi et al., 2018), the functional relationship between the dimension parameters has been achieved and presented in equation (3).

$$
\frac{\mathrm{Q}}{\mathrm{g}^{\frac{1}{2}} \mathrm{~h}^{\frac{5}{2}}}=\mathrm{f}\left[\frac{\mathrm{h}}{\mathrm{P}}, \frac{\mathrm{h}}{\mathrm{L}}, \frac{\mathrm{h}}{\mathrm{B}}, \frac{\mathrm{h}}{\mathrm{H}}, \mathrm{a}\right]
$$

Where the value of $\frac{\mathrm{Q}}{\mathrm{g}^{\frac{1}{2}} \mathrm{~h}^{\frac{5}{2}}}$ defined by (Bijankhan and Ferro, 2017) as discharge coefficient Cd. The findings of (Noui and Ouamane, 2011) states that the ratio of apex width to the weir length $\left(\frac{\mathrm{a}}{\mathrm{L}}\right)$ and the ratio of apex width to the weir height $\left(\frac{\mathrm{a}}{\mathrm{P}}\right)$ have a significant effect on the discharge coefficient, Therefore, these two parameters added to Eq. (3) Became:

$$
\mathrm{Cd}=\mathrm{f}\left[\frac{\mathrm{h}}{\mathrm{P}}, \frac{\mathrm{h}}{\mathrm{L}}, \frac{\mathrm{h}}{\mathrm{B}}, \frac{\mathrm{h}}{\mathrm{H}}, \mathrm{a}, \frac{\mathrm{a}}{\mathrm{L}}, \frac{\mathrm{a}}{\mathrm{P}}\right]
$$

The data collected from the experimental work was according to the flow chart was presented in Fig. (2):

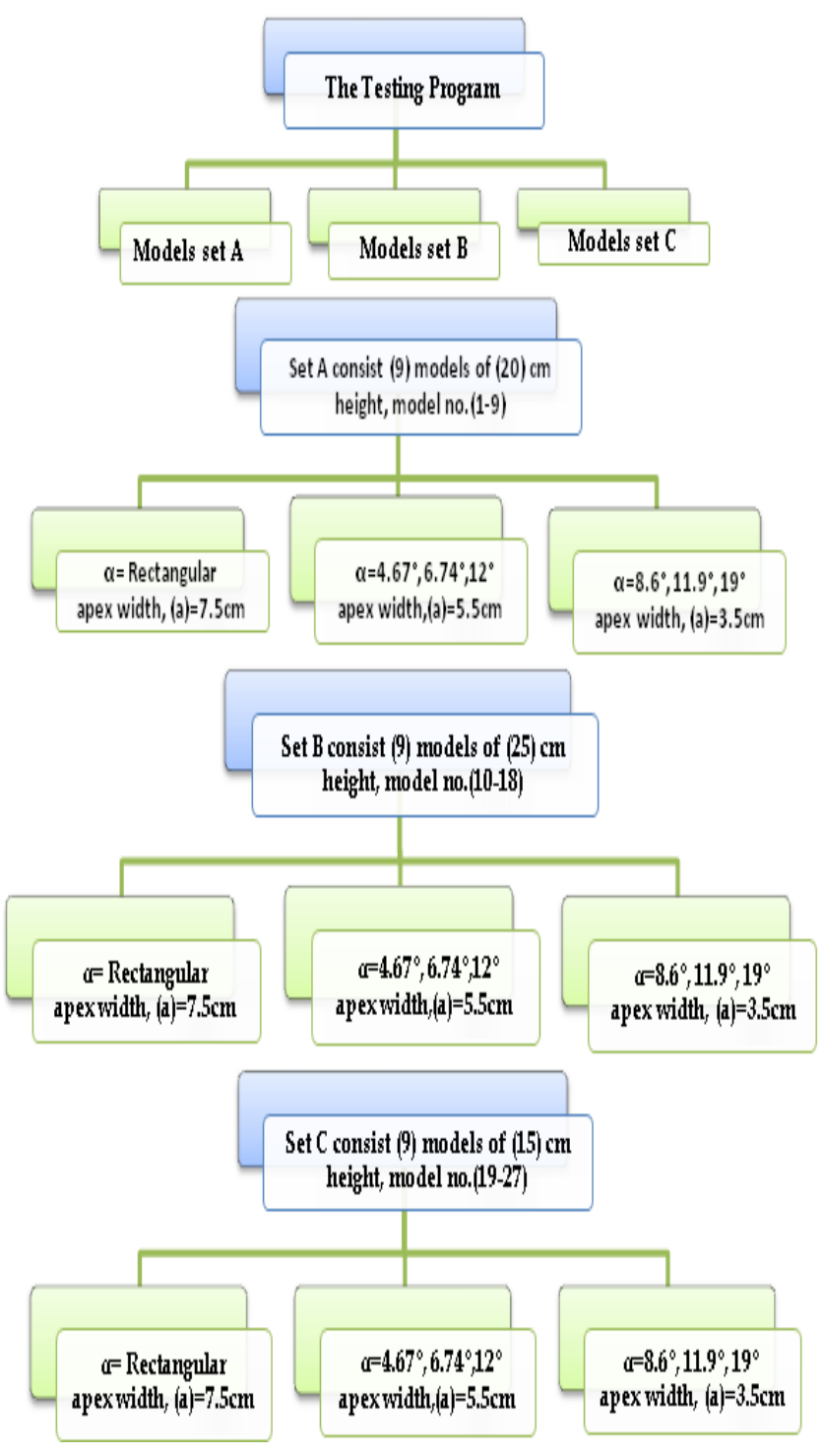

Fig. 2: The flow chart of the model testing.

\section{EXPERIMENTAL SETUP AND EXPERIMENTS:}

The experiments were carried out at the Hydraulic Laboratory of the Water Resources Department in the College of Engineering of Duhok University. The experiments were conducted in a rectangular flume with dimensions $(0.3 \mathrm{~m}$ width, $0.45 \mathrm{~m}$ height, and $5 \mathrm{~m}$ length). The water surface profile head upstream is measured by an accurate point gauge was $0.1 \mathrm{~mm}$ and the discharge measured by ultrasonic digital meter with an accuracy of 0.01 liters/sec which was calibrated with normal weir. Twenty-seven models of sharp-crested labyrinth weirs were tested in the experiment with two cycles. The models classified into three groups depending on the height of the weir $(\mathrm{P}=15,20$, and $25 \mathrm{~cm})$, each group consisting of a 
rectangular labyrinth weir and trapezoidal labyrinth weir with different sidewall angle $\left(4.67^{\circ}\right.$ to $\left.19^{\circ}\right)$, sidewall length (lc), and apex width (a) as shown in Table (1). The upstream head to the weir height ranged from $(0.08-0.48)$ and the Froude number is ranged from (0.095-0.235) for the approach channel.

Table 1: Details of the physical models testing the experiment.

\begin{tabular}{|c|c|c|c|c|c|c|c|}
\hline $\begin{array}{c}\text { Model } \\
\text { No. }\end{array}$ & $\begin{array}{c}\text { Height } \\
\text { of } \\
\text { weir P } \\
\text { (cm) }\end{array}$ & $\begin{array}{c}\text { Channel } \\
\text { width B } \\
\text { (cm) }\end{array}$ & $\begin{array}{c}\text { No. } \\
\text { of } \\
\text { cycle } \\
\text { N }\end{array}$ & $\begin{array}{l}\text { Sidewall } \\
\text { angles a } \\
\text { (degree) }\end{array}$ & $\begin{array}{l}\text { Apex } \\
\text { width } \\
\text { a } \\
\text { (cm) }\end{array}$ & $\begin{array}{l}\text { Sidewall } \\
\text { length lc } \\
\text { (cm) }\end{array}$ & L/B \\
\hline 1 & & 30 & 2 & Rectangular & 7.5 & 7.5 & 2 \\
\hline 2 & & 30 & 2 & Rectangular & 7.5 & 15 & 3 \\
\hline 3 & 15, & 30 & 2 & Rectangular & 7.5 & 22.5 & 4 \\
\hline 4 & & 30 & 2 & 12 & 5.5 & 9.72 & 2 \\
\hline 5 & & 30 & 2 & 6.74 & 5.5 & 17.12 & 3 \\
\hline 6 & & 30 & 2 & 4.67 & 5.5 & 24.58 & 4 \\
\hline 7 & 25 & 30 & 2 & 19 & 3.5 & 12.26 & 2 \\
\hline 8 & & 30 & 2 & 11.9 & 3.5 & 19.42 & 3 \\
\hline 9 & & 30 & 2 & 8.6 & 3.5 & 26.80 & 4 \\
\hline
\end{tabular}

\section{RESULTS AND DISCUSSIONS}

The results of the study measurements show that for a certain value of flow, head, the discharge increases with an increase in the sidewall length (lc) as shown in Fig. (3), but the discharge coefficient is increased by decreasing the sidewall length (lc) due to the increase in the total length. Since the length of the sidewall increases as the sidewall angle decreases for the same apex width, therefore, the discharge coefficient decreases as presented in Fig. (4) for apex width (a) equal to $5.5 \mathrm{~cm}$.

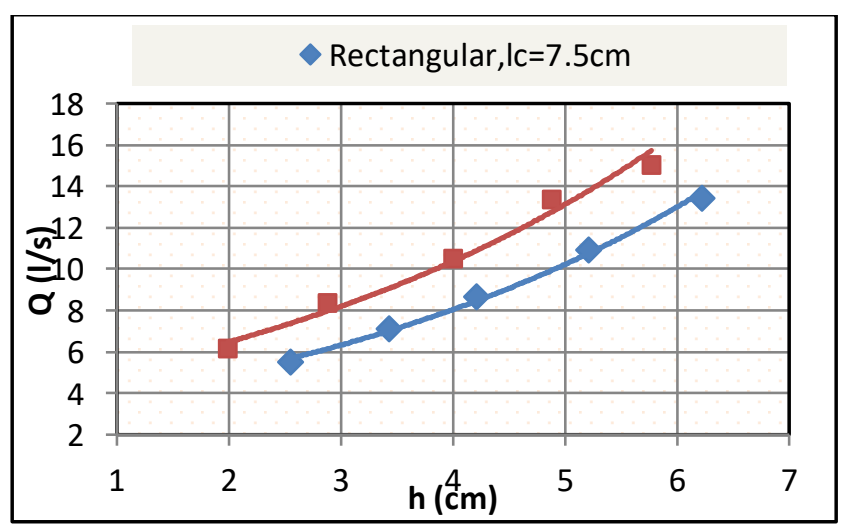

Fig. 3: Variation of $Q \& h$ for two labyrinths (Rectangular, $\mathrm{lc}=7.5 \mathrm{~cm})$.

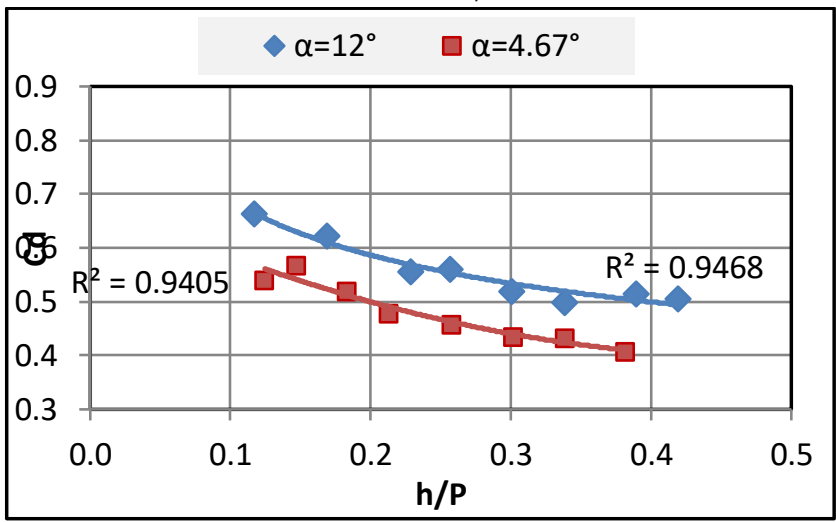

Fig. 4: Variation of $\mathrm{Cd}$ with $\mathrm{h} / \mathrm{P}$ for two labyrinths $(\mathrm{P}=\mathbf{1 5} \mathrm{cm})$.

The performance of the labyrinth weir (Q) is compared with the normal weir (Qn), which is shown to have higher efficiency than the normal weir $\mathrm{s}$ about 2.5 in low head and 1.5 in the high head as shown in Fig. (5)

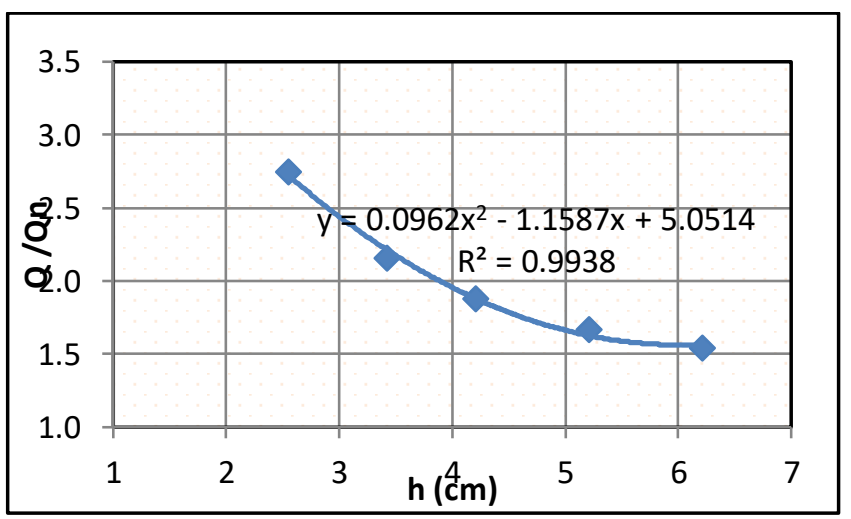

Fig. 5: Variation of $h$ with $Q / Q n$ for $(P=15 \mathrm{~cm})$. Moreover, the results of the data for the experiments are shown in Fig.(6) for all models. The Figs. show the value of discharge coefficient $(\mathrm{Cd})$ decreases with increases in the ratio of upstream head to the weir height $(\mathrm{h} / \mathrm{P})$ for all models which also proved by Tullis et al. (1995), and the discharge coefficient decreases with increases of the height $(P)$ of the weir the same thing was proved by Gupta et al. (2015). 

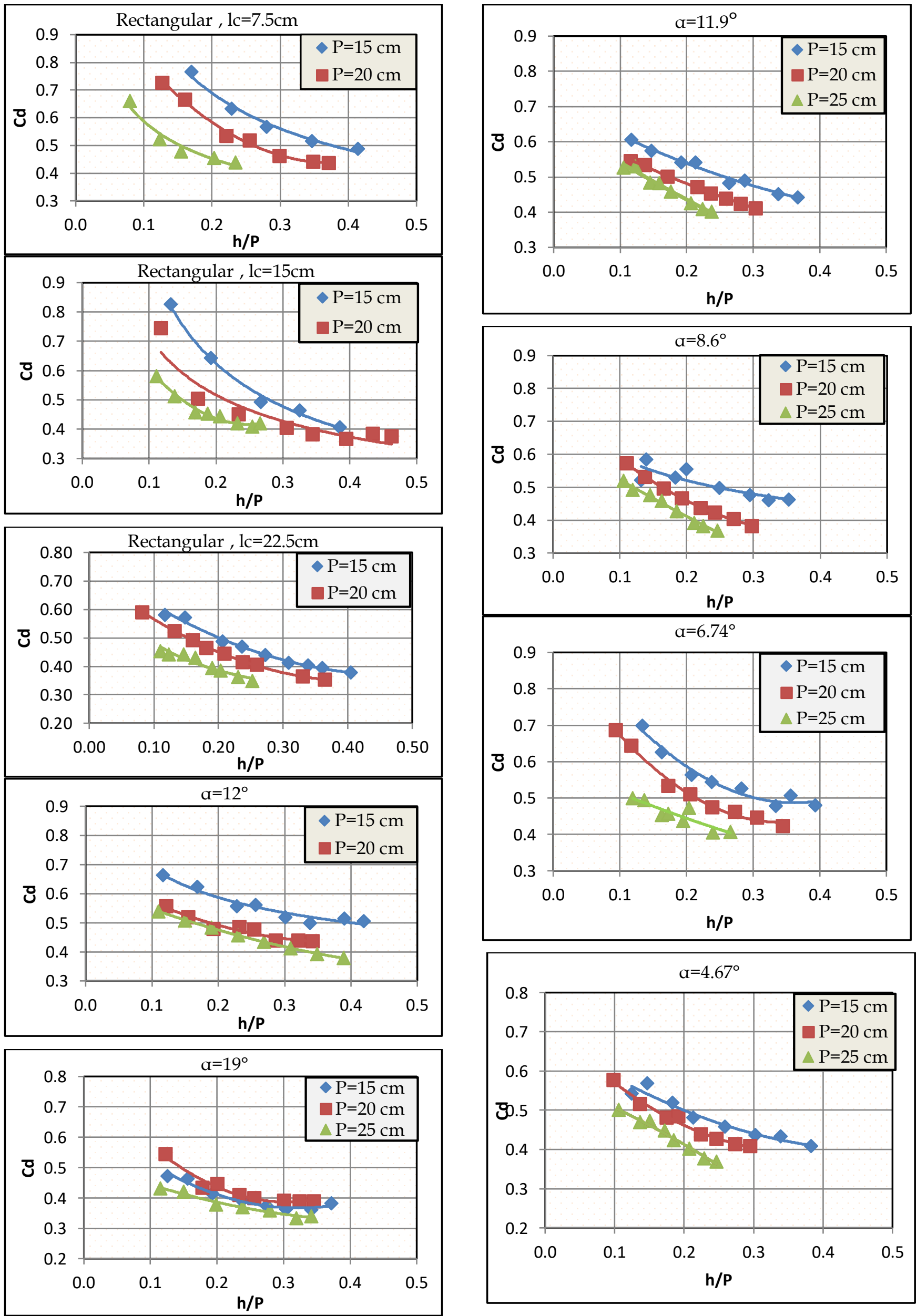

Fig. 6: Variation of $\mathrm{Cd}$ with $\mathrm{h} / \mathrm{P}$ for labyrinth weirs. 
The comparison between nearly the same total length of labyrinth weirs indicates that the value of discharge coefficient is increased when the apex width (a) is increased as presented in Fig. (7), this observation agrees with the results of (Khode et al., 2012)

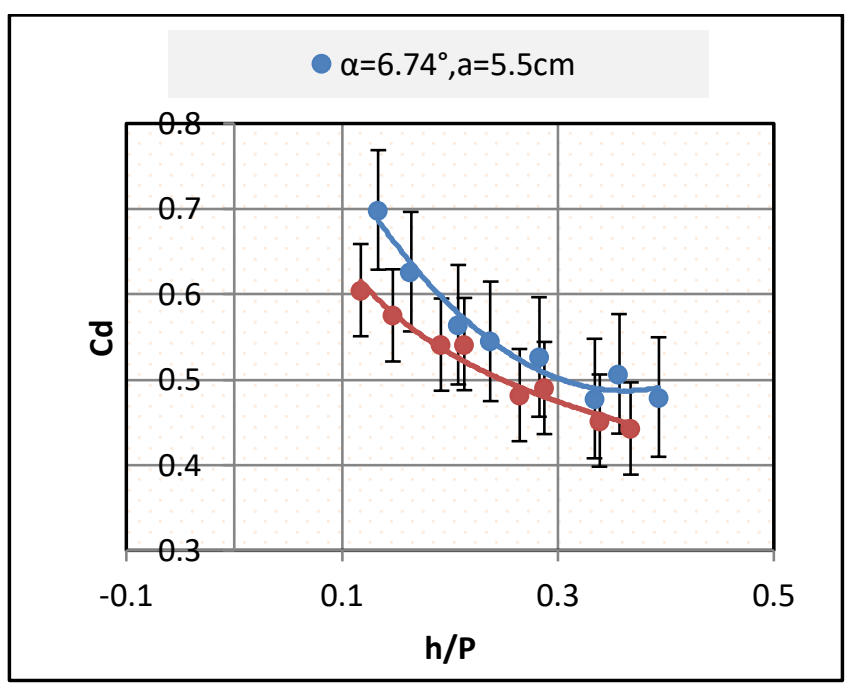

Fig. 7: Variation of $\mathrm{Cd}$ with $\mathrm{h} / \mathrm{P}$ for the same labyrinth weir heights.

The measurements of water surface profiles at the centerline indicate that the curvature profile depends on the length of the sidewall (lc). Fig. (8) and the image on Fig. (9) show that for the long side wall, the water surface profile falls to a certain level along the sidewall, and then after some distance, the curvature takes another shape. This behavior also depends on the width of the apex wall part and weir height, it can be noted from the Figs. also, that in the models with a short sidewall length $(\mathrm{lc})$, the curvature of the water surface profile seems to be nearly like that of a normal weir. The shape of the water surface profile can relate to the percentage part of the discharge which falls from the long side walls, the longest is the sidewalls the more is the percentage falls from their crests, and the remaining discharge falls from the apex wall. The remaining flow part hits the apex wall and generates a profile curvature depending on the apex wall width

(a) and the approaching flow velocity.

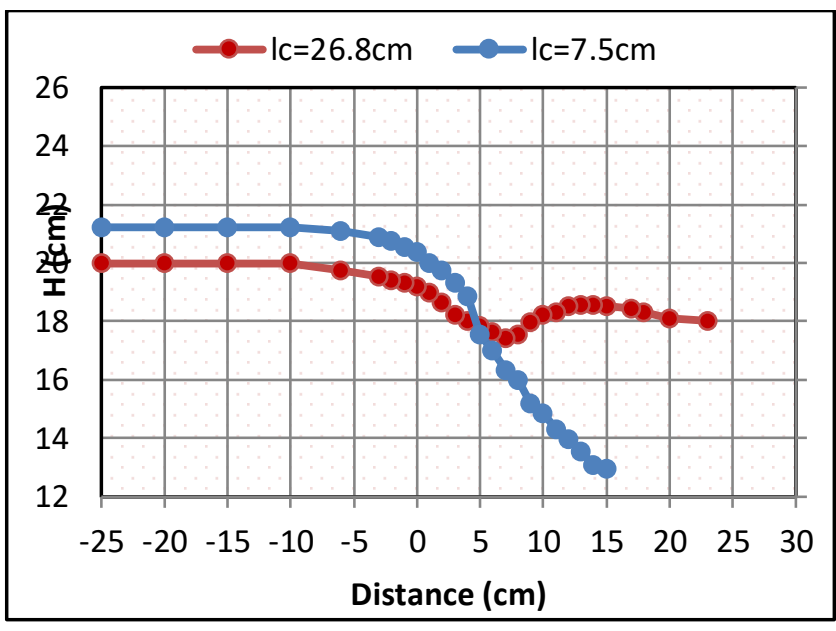

Fig.(8): Difference between profiles of water surface of different sidewall lengths.

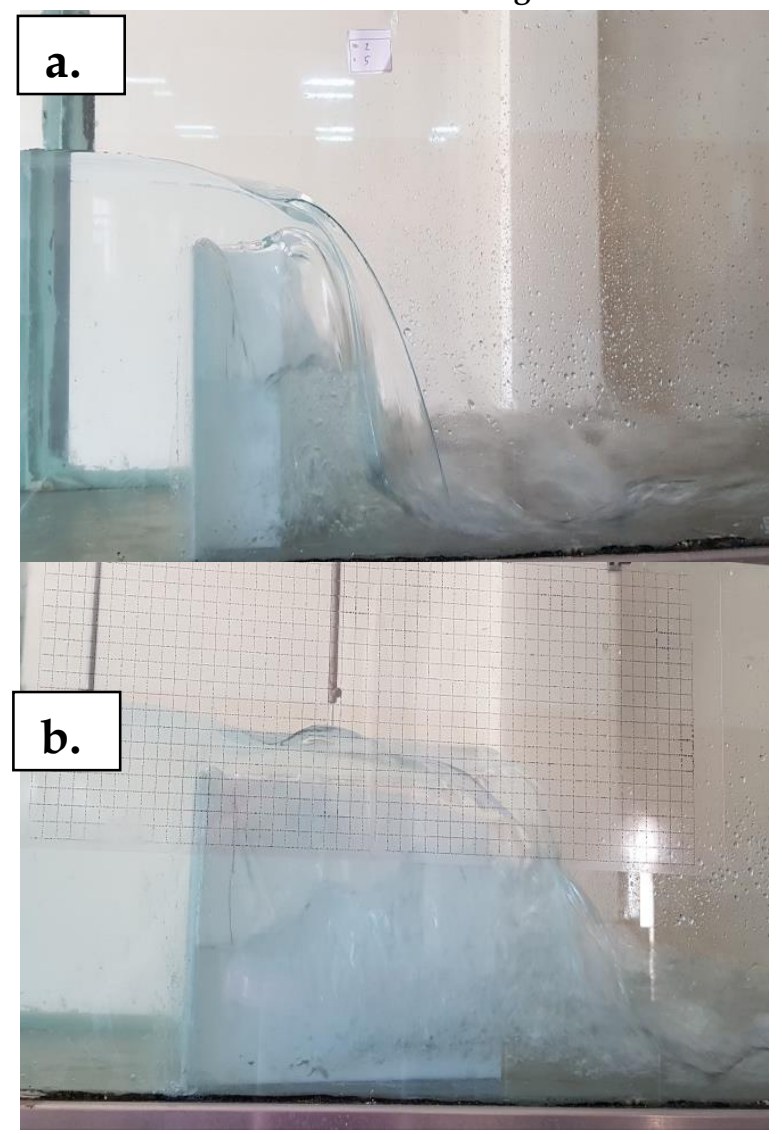

Fig. (9): Water surface profiles in the Lab. (a) $1 \mathrm{c}=15 \mathrm{~cm}$ (b) $1 \mathrm{c}=26.8 \mathrm{~cm}$.

To show the effect of each side length (lc) on the trend of discharge coefficient variation with $h / P$, two different lengths of the sidewall are chosen for the present study, and another two from Khode et al., 2012 and from Ghaderi et al., 2020. The chosen lengths are presented in Fig. (10). The trends of variations in the discharge coefficient value are nearly the same as those studies of Khode et al., and from Ghaderi et al. It can be noted that the rate of variation 
in the value of discharge coefficient is less and nearly constant for the shorter sidewall, while that variation has a steeper slope at the beginning of the study rage. According to the above description of the effect of side length and apex width, it was difficult to create one prediction equation for all models using wellknown statistical regression. The water surface profile was followed for all models and then separate into two groups according to the percentage value of apex width to sidewall length. From the experimental data, the dimensionless parameters in Eq. (4) have been calculated and correlated to the discharge coefficient has been carried using the SPSS software package. Two regression models have been generated for each group. The prediction equations are listed below:

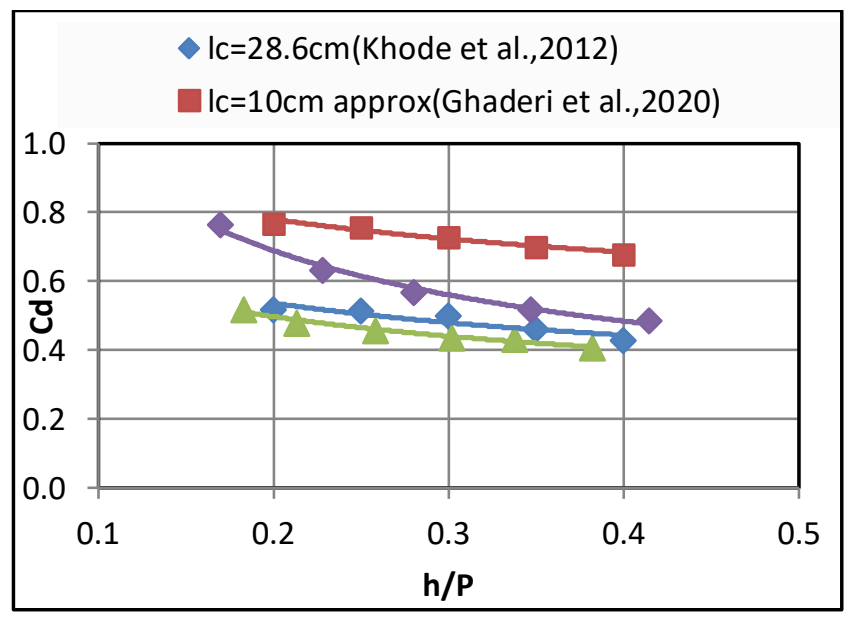

Fig.(10): Variation of $\mathrm{Cd}$ with $\mathrm{h} / \mathrm{P}$ for four labyrinth weir.

\begin{tabular}{|c|c|c|c|}
\hline No & Equation & $\mathrm{a} / \mathrm{lc}$ & $\mathbf{R}^{2}$ \\
\hline 1. & $C d=0.49+2.72\left(\frac{h}{P}\right)-6.2\left(\frac{h}{H}\right)-0.11\left(\frac{h}{B}\right)+0.1$ & 05 & $\begin{array}{l}0 . \\
86 \\
0\end{array}$ \\
\hline 2. & $\begin{array}{c}\mathrm{Cd}=-2.35-0.75\left(\frac{\mathrm{h}}{\mathrm{P}}\right)^{0.36}+3.35\left(\frac{\mathrm{h}}{\mathrm{H}}\right)^{0.07}+0.06( \\
+12.1\left(\frac{\mathrm{a}}{\mathrm{L}}\right)^{2.64}+0.05(\mathrm{a})^{-0.38}\end{array}$ & $\begin{array}{c}0.5- \\
1.0\end{array}$ & $\begin{array}{l}0 . \\
90 \\
2\end{array}$ \\
\hline 3. & $\begin{array}{c}\mathrm{Cd}=0.61+0.86\left(\frac{\mathrm{h}}{\mathrm{P}}\right)-0.8\left(\frac{\mathrm{h}}{\mathrm{H}}\right)-2.03\left(\frac{\mathrm{h}}{\mathrm{B}}\right)+0.5 \\
-0.02(\mathrm{a})\end{array}$ & 0.13 & $\begin{array}{l}0 . \\
90 \\
8\end{array}$ \\
\hline 4. & $\begin{array}{c}C d=-275.18-128\left(\frac{h}{\mathrm{P}}\right)^{0.01}-5.67\left(\frac{\mathrm{h}}{\mathrm{H}}\right)^{0.16}+79.4 \\
\left(\frac{\mathrm{a}}{\mathrm{P}}\right)^{-0.02}+16\left(\frac{\mathrm{a}}{\mathrm{L}}\right)^{1.81}+0.3(\mathrm{a})^{-0.01}\end{array}$ & 0.33 & $\begin{array}{l}0 . \\
94 \\
9\end{array}$ \\
\hline
\end{tabular}

The mean values of the discharge coefficient $(\mathrm{Cd})$ with the error bar analysis shown in Fig. (11) for all models having $15 \mathrm{~cm}$ height. The highest value of the mean discharge coefficient is 0.62 for model no. 1 which has the wide apex width $(\mathrm{a})=7.5 \mathrm{~m}$.

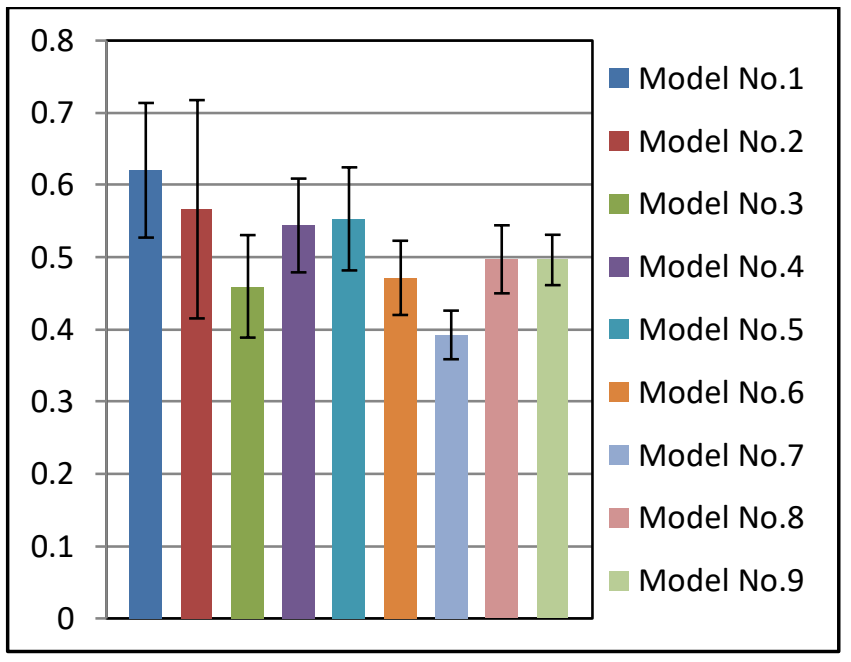

Fig. (11): Error Bar Analysis of Cd Values for all models with $P=15 \mathrm{~cm}$.

The Artificial Neural Network (ANN) is the nonlinear mathematical model used for finding the regression between the observed and calculated data of the discharge coefficient ( $\mathrm{Cd}$ ) by MATLAB program. The data entered into the input layer and the data pass from the hidden layer and puts the results in the output layer. (Norouzi et al. 2019)

The dimensional analysis parameters $(\mathrm{h} / \mathrm{P}, \mathrm{h} / \mathrm{H}, \mathrm{h} / \mathrm{B}$, $\mathrm{h} / \mathrm{a}, \mathrm{a} / \mathrm{P}, \mathrm{a} / \mathrm{L}$, and $\mathrm{a}$ ) are used as the input for the neural network model, 10 hidden layers, and the discharge coefficient $(\mathrm{Cd})$ is the output of the neural network for all physical models tested in the present study shown in Fig.(12). 


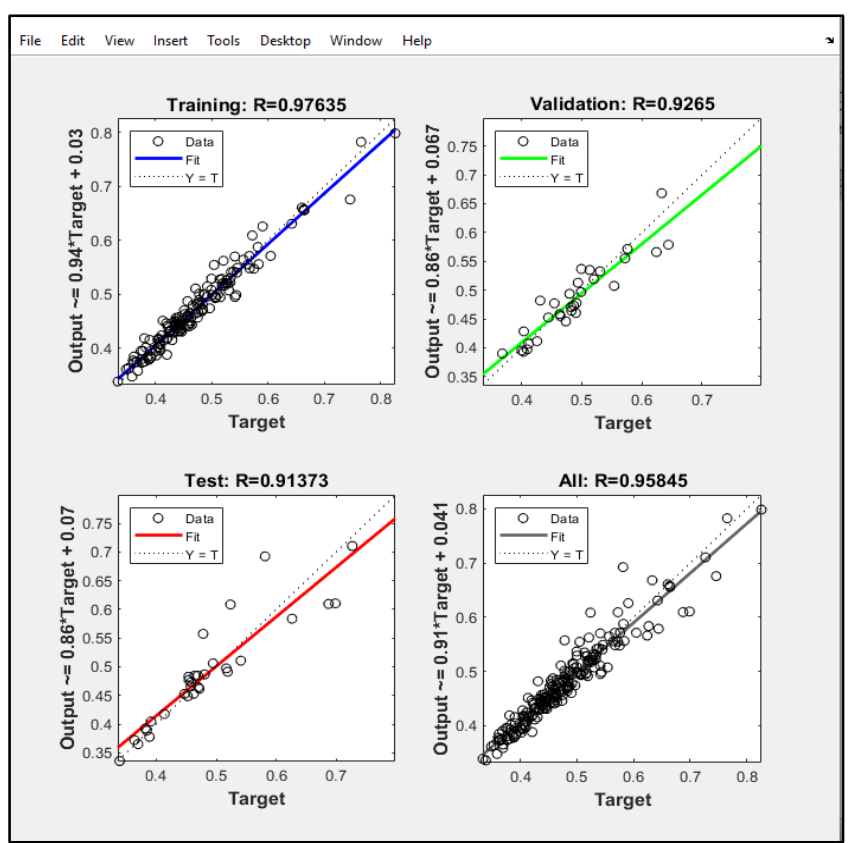

Fig. (12): Regression plot by Neural Network model.

After 15 iterations the artificial neural network was able to predict the values of discharge coefficient for all tested models with acceptable $\mathrm{R}=0.958$.

The percentage error for the value of $\mathrm{Cd}$ predicted and Cd observed is between $-10 \%$ and $+10 \%$ for all models and presented in Fig. (13)

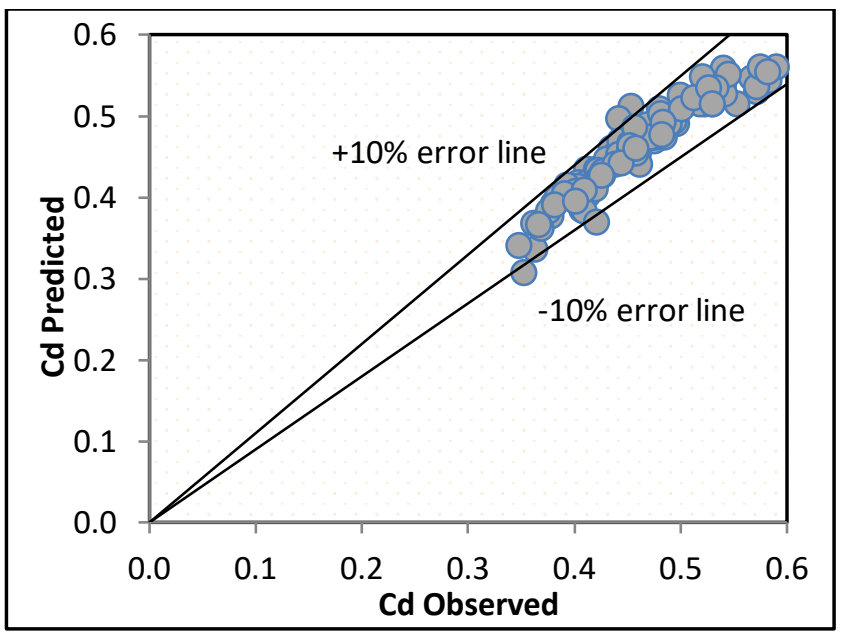

Fig. (13): Percentage error of Cd predicted and Cd observed in the experiment for all models.

\section{CONCLUSIONS:}

The experimental results indicate that such weirs have a higher efficiency than normal weirs of the same height. The discharge over two cycles labyrinth weir is 2.5 to 1.5 more than that over a normal weir for the same range of flow head due to their longer crest. The performance decreases with the increase of weir height due to the increase of streamline curvature. The sidewall weir length affects the curvature of the nappe flow, which became a flatter surface profile with the increase, due to the more portion of the discharge that can be passed over them. As such type weirs can be used in narrow channels to avoid lifting the water surface level in the irrigation delivery system, the highest average discharge coefficient is 0.62 for model 1 . The results can be summarized in the following points.

- $\quad$ The increase in sidewall length (lc) has a positive effect on the flow discharge; also it will increase the total effective weir length and then increasing the theoretical value of discharge which causes a reduction in discharge coefficient.

- The discharge coefficient (Cd) decreases with the increase of the $\mathrm{h} / \mathrm{p}$ ratio, and the lower weir height of $15 \mathrm{~cm}$ performs better than the higher one of $25 \mathrm{~cm}$.

- The discharge coefficient $(\mathrm{Cd})$ increases with the increases in the apex width (a) for the same total effective length.

- For the constant value of apex width, the discharge coefficient decreases (Cd) when the sidewall angle decreases.

- Prediction of equations for the value of the discharge coefficient is suggested.

\section{Limitation of the study}

- The experimental work limited by a $30 \mathrm{~cm}$ wide channel, and according to the earlier studies that the two cycles labyrinth weir is more efficient so that the models were limited by three apex width $(3.5,5.5,7.5 \mathrm{~cm})$ and accordingly the sidewall angles $(\alpha)$ is also limited from $\left(4.67^{\circ}\right.$ to $\left.19^{\circ}\right)$. The value of Froude's number in the approach part of the channel is ranged from $(0.095-0.235)$ and the ratio of the upstream head to the weir height $(\mathrm{h} / \mathrm{P})$ is ranged $(0.08-0.48)$.

- Studies can be carried on the modification of the sharp crest edge to a half-round, quarter, or 
round crested also can be tested in the wider channel to get more range of models.

\section{REFERENCES}

1. Abbasi, S., Ghaderi, A., Abraham, J., \& Azamathulla, H. M. (2020). Efficiency of trapezoidal labyrinth shaped stepped spillways. Flow Measurement and Instrumentation, 72, 101711.

2. Bijankhan, M. and Ferro, V., (2017). "Dimensional analysis and stage-discharge relationship for weirs", a review. Journal of Agricultural Engineering, 48(1), pp.1-11.

3. Bilhan, O. and Emiroglu, M.E., (2016). "Experimental Studies on Determination of Discharge Capacity of Circular Labyrinth Weirs Located on a Straight Channel", International Journal of Electronics, Mechanical, and Mechatronics Engineering (IJEMME), 6(3), pp.1227-1239.

4. Carollo, F.G., Ferro, V., and Pampalone, V., (2011). "Experimental investigation of the outflow process over a triangular labyrinth-weir", Journal of Irrigation and Drainage Engineering, 138(1), pp.73-79.

5. Chow, V.T., 1959.Open-Channel Hydraulic. McGrawHill Book Co., New York.

6. Crookston, B.M., (2010). "Labyrinth weirs" (Doctoral dissertation), University of Utah state.

7. Crookston, B.M., and Tullis, B.P., (2011). "Discharge efficiency of reservoir-application-specific labyrinth weirs", Journal of Irrigation and Drainage Engineering, 138(6), pp.564-568.

8. Crookston, B.M., and Tullis, B.P., (2012). "Labyrinth weirs: Nappe interference and local submergence". Journal of Irrigation and Drainage Engineering, 138(8), pp.757-765.

9. Dabling, M.R., and Crookston, B.M., (2012). "Staged and notched labyrinth weir hydraulics", International junior research and engineer workshop on hydraulic structures, Ulah state university.

10. Ghaderi, A., Daneshfaraz, R., Dasineh, M., and Di Francesco, S., 2020. Energy Dissipation and Hydraulics of Flow over Trapezoidal-Triangular Labyrinth Weirs. Water, 12(7), p.1992.

11. Ghare, A.D., Mhaisalkar, V.A. and Porey, P.D., (2008). "An approach to optimal design of trapezoidal labyrinth weirs", World applied sciences journal, 3(6), pp.934-938.

12. Gupta, K.K., Kumar, S., and Ahmad, Z., (2015). “Effect of weir height on flow performance of sharp-crested rectangular-planform weir", World Appl. Sci. J, 33(1), pp.168-175.

13. Hicks, A., \& Slaton, W. (2014). Determining the coefficient of discharge for a draining container. The Physics Teacher, 52(1), 43-47.

14. Horton, R. E. (1907). Weir experiments, coefficients, and formulas: US Geol. Survey Water-Supply Paper, 200, 195, https:// pubs.usgs.gov/wsp/0200/report.pdf
15. Idrees, A.K., Al-Ameri, R., and Das, S., (2016). "Determination of discharge coefficient for flow over one cycle compound trapezoidal plan form labyrinth weir", International journal of civil engineering and technology, 7(4), pp.314-328.

16. Khode, B. V., Tembhurkar, A. R. P. D. Porey and R. N. Ingle, (2012). "Experimental Studies on Flow over Labyrinth Weir", Journal of Irrig. Drain Eng. ASCE, 138:548-552.

17. Khode, B.V., and Tembhurkar, A.R., (2010). "Evaluation and analysis of crest coefficient for labyrinth weir", World applied sciences journal, 11(7), pp.835-839.

18. Khode, B.V., Tembhurkar, A.R., Porey, P.D., and Ingle, R.N., (2011). "Determination of crest coefficient for flow over trapezoidal labyrinth weir", World Applied Sciences Journal, 12(3), pp.324-329.

19. Mirnaseri, M. and Emadi, A., (2013). "Hydraulic performance of combined flow rectangular labyrinth weir-gate", Middle. East. J. Sci. Res, 18(9), pp.13351342.

20. Norouzi, R., Daneshfaraz, R. and Ghaderi, A., 2019. "Investigation of discharge coefficient of trapezoidal labyrinth weirs using artificial neural networks and support vector machines". Applied Water Science, 9(7), p.148.

21. Noui, A., and Ouamane, A., 2011, May. "Study of optimization of the Piano KeyWeir". In Proc IntConf Labyrinth Piano Key Weirs-PKW2011, London: Taylor \& Francis (pp. 175-82).

22. Paxson, G. and Savage, B., (2006). "Labyrinth spillways: comparison of two popular USA design methods and consideration of non-standard approach conditions and geometries", In Proceedings of the. International Junior Researcher and Engineer Workshop on Hydraulic Structures (pp. 37-46).

23. Sangsefidi, Y., Mehraein, M., \& Ghodsian, M. (2018). Experimental study on flow over In- reservoir arced labyrinth weirs. Flow Measurement and Instrumentation, 59, 215-224.

24. Savage, B., Frizell, K., and Crowder, J., (2004). “Brains versus brawn: the changing world of hydraulic model studies", In Proceedings of the 2004 annual conference, Association of State Dam Safety Officials (ASDSO), Phoenix, USA.

25. Sitompul, A.T., (1993). "Hydraulic modeling of a sharpcrested labyrinth weir (Doctoral dissertation", Memorial University of Newfoundland).

26. Subramanya, (2009) "Flow in open channels", Third Edition, Tata Mc Graw Hill Edition Private Limited, New Delhi, India.

27. Suprapto, M. (2013). “Increase Spillway Capacity using Labyrinth Weir", The 2nd International Conference on Rehabilitation and Maintenance in Civil Engineering, (pp. 440-446).

28. Tacail, F.G., Evans, B., and Babb, A. (1990). "Case study of a labyrinth weir spillway". Canadian Journal of Civil 
Engineering, National Research Council Canada, Vol. 17, pp. 1-7.

29. Taylor, G., (1968). "The performance of labyrinth weirs" (Doctoral dissertation, University of Nottingham).

30. Tullis, B.P., Young, J.C., and Chandler, M.A., (2007). "Head-discharge relationships for submerged labyrinth weirs", Journal of Hydraulic Engineering, 133(3), pp.248-254.

31. Tullis, J.P., Amanian, N., and Waldron, D., (1995). "Design of labyrinth spillways", Journal of hydraulic engineering, 121(3), pp.247-255.

32. Willmore, C.M.,(2004). "Hydraulic characteristics of labyrinth weirs".

33. Wormleaton, P., and Tsang, C. (2000). "Aeration performance of rectangular planform labyrinth weirs", J. of Environ. Engrg., ASCE, 127(5), 456-465. 